\title{
EVALUATION OF PHYTOCHEMICAL ANALYSIS AND ANTIOXIDANT AND ANTIFUNGAL ACTIVITY OF PITHECELLOBIUM DULCE LEAVES' EXTRACT
}

\author{
SUMAN KUMARI* \\ Department of Biochemistry, Maharshi Dayanand University, Rohtak, Haryana, India. Email: sumanraotatla@gmail.com
}

Received: 07 October 2016, Revised and Accepted: 14 October 2016

ABSTRACT

Objective: Diseases due to pathogenic fungi represent a critical problem to human health which is a major cause of morbidity and mortality worldwide. Synthetic drugs such as Amphotericin B mitigate many of the side effects associated with liver and kidney dysfunctions. Widely distributed traditional medicinal plants-based antimicrobial drugs are cost effective in the treatment of infectious diseases having no side effects. Pithecellobium dulce (Roxb.) belongs to the family of Leguminosae, is an evergreen tree widely distributed in the greater part of India which has been widely used in traditional medicine, but lacks scientific scrutiny. The present study revealed $P$. dulce extract effectiveness against A. fumigates and Aspergillus niger and showed antioxidant activity.

Methods: Leaves' extract was prepared according to the polarity of solvent, i.e., hexane, chloroform, acetone, methanol, and water. Phytochemical analysis, antioxidant activity, and minimum inhibitory concentration (MIC) were tested against selected fungus.

Results: Phytochemical analysis of the extract revealed the presence of alkaloids, flavonoids, saponins, coumarin, tannins, anthocyanin, and triterpenoids. Methanol and water extract was found to contain significant amounts of alkaloids, phenols, and flavonoids. Methanolic extract showed MIC against tested fungus, and extract was further fractionated by solvent-solvent fractionation and MIC was tested. MIC for A. fumigatus was $0.62 \mathrm{mg} / \mathrm{ml}$ and for A. niger was $1.25 \mathrm{mg} / \mathrm{ml}$, and the results were comparable with effective synthetic drug Amphotericin B.

Conclusion: Extract possesses potent fungicidal activity which, in turn, may be due to the presence of biologically active ingredient.

Keywords: Antioxidant activity, Phytochemical activity, Antifungal activity, Minimum inhibitory concentration, Fractionation.

(C) 2017 The Authors. Published by Innovare Academic Sciences Pvt Ltd. This is an open access article under the CC BY license (http://creativecommons. org/licenses/by/4. 0/) DOI: http://dx.doi.org/10.22159/ajpcr.2017.v10i1.15576

\section{INTRODUCTION}

Medicinal flora has versatile applications attributable to richest bioresource of drugs in Indian Ayurveda (traditional medicines), modern pharmaceutical intermediates, and chemical entities for synthetic drugs formation. Bioresources are primary (carbohydrates, proteins, and amino acids) and secondary metabolites (steroids, flavonoids, phenolics, glycosides, saponins, tannins, terpenoids, and coumarins) that impart medicinal properties to the plants. The current advancement to discover drugs from natural sources has resulted in compounds that are being developed to treat cancer, resistant bacteria, fungus, protozoa, or viruses and immunosuppressive disorders [1].

Pithecellobium dulce (Roxb.) Benth (Syn. Mimosa dulcis Roxb.; Inga dulcis Wild.; Inga lanceolata Blanco.) belongs to family Leguminosae, is an evergreen tree widely distributed in India, and is also found in Southeast Asia. Plant locally is known by various names at different regions, namely, Hindi - Vilayati babul, vilayati imli, jungle jalebi; English - Quamachil, Madras thorn, and manila tamarind. Various parts of plant are used for different purposes such as leaves have been reported to possess abortifacient, antidiabetic properties, emollient, anticonvulsant, and antiulcer. The leaves can be applied as plasters for pain and venereal sores. Decoctions of leaves have been reported to be used for indigestion, intestinal disorder, earache, toothache, leprosy, and larvicide [2]. The bark of the plant is reported to be used as astringent in dysentery, febrifuge, and it is also useful in dermatitis and eye inflammation.

P. dulce is one of the traditional medicinal plants that lack scientific examination for its pharmacological properties. Oxidative stress resulted from free radicals and reactive oxygen species are associated with many diseases. Several studies are going on worldwide directed toward finding natural antioxidants of plant origin. Plants containing secondary metabolites such as phenolic compounds have been reported to possess strong antioxidant activity. The aim of the present study was to screen phytochemical constituents, in vitro antioxidant activity, and antifungal of $P$. dulce Benth. in different solvents according to their polarity.

\section{METHODS}

\section{General}

Folin-Ciocalteu reagent, $\mathrm{Na}_{2} \mathrm{CO}_{3}$, potassium ferricyanide [K3Fe(CN)6], trichloroacetic acid, $\mathrm{FeCl}_{3}$, 1,1-diphenyl-2-picrylhydrazyl (DPPH), nitro blue tetrazolium, NADH, phenazine methosulfate, 2-deoxyribose, $\mathrm{FeSO}_{4}$-EDTA, thiobarbituric acid (TBA), $\mathrm{NaOH}, 2$-deoxyribose, $\mathrm{FeSO}_{4}$ EDTA, TBA, and $\mathrm{NaOH}$ were purchased from Hi-Media.

\section{Extract preparation}

The leaves of the plant $P$. dulce growing in the local areas of Rohtak district of Haryana State were collected during January 2015. The plant material was washed thoroughly, initially with tap water and then with distilled water to remove any debris or dust particles, further allowed to dry in shade. The dried plant material was ground to a fine powder and stored at room temperature in airtight containers until used further. To $500 \mathrm{~g}$ of leaf powder, $1500 \mathrm{ml}$ of each solvent, namely, hexane, chloroform, acetone, methanol, and distilled water, was added serially for preparing the extracts in increasing solvent polarity. Extraction with each solvent was done for $72 \mathrm{hrs}$ at room temperature in the shaker with the rotation of $250 \mathrm{rpm}$, after 
which the supernatant of each solvent was recovered by filtering through Whatman filter paper. This process was repeated twice, and the respective solvent from the supernatant was evaporated in a rotary vacuum evaporator to obtain the crude extract. These extracts were stored in falcon tube at $-20^{\circ} \mathrm{C}$, and its mouth is closed with parafilm until used for the evaluation of antimicrobial and other activities.

\section{Determination of percentage yield of plant extract}

The percentage yield of the plant extract was obtained using the formula, extraction yield $(\%)=w 1 \times 100 / w 2$ where $w 1=$ Weight of dried crude plant extract (after extraction); w2=Weight of the dried plant material (before extraction). The percentage yield of the plant extract obtained was $0.565 \%, 18.70 \%, 21.53 \%, 56.60 \%$, and $74.99 \%$ in hexane, chloroform, acetone, methanol, and water, respectively.

\section{Preliminary phytochemical analysis of the extracts}

To assess the chemical composition of the various extracts qualitatively, a preliminary phytochemical analysis was conducted according to the standard methods. Using these methods, the presence of several phytochemicals such as alkaloids, saponins, terpenoids, phlobatannins, coumarin, tannin, flavonoids, and anthraquinones was evaluated.

\section{Test for alkaloids}

$0.4 \mathrm{~g}$ of plant extract was stirred with $8 \mathrm{ml}$ of $1 \% \mathrm{HCl}$, and the mixture was warmed and filtered [3]. $2 \mathrm{ml}$ of filtrate was treated separately with (a) few drops of Mayer's reagent and (b) few drops of Dragendorff's reagent. Turbidity or precipitation with either of these reagents was taken as evidence for existence of alkaloids.

\section{Test for saponin}

$1 \mathrm{~g}$ of each extract was boiled with $5 \mathrm{ml}$ of distilled water and filtered. To the filtrate, about $3 \mathrm{ml}$ of distilled water was further added and shaken vigorously for about 5 minutes. Frothing which persisted on warming was taken as evidence for the presence of saponins [3].

\section{Test for terpenoids (Salkowski test)}

To $0.5 \mathrm{~g}$ of each extract, $2 \mathrm{ml}$ of chloroform was added, followed by a further addition of $3 \mathrm{ml}$ of concentrated sulfuric acid $\left(\mathrm{H}_{2} \mathrm{SO}_{4}\right)$ to form a layer. A reddish brown coloration of the interface indicated the presence of terpenoids [3].

\section{Test for phlobatannins}

$80 \mathrm{mg}$ of plant extract was boiled in $1 \%$ aqueous $\mathrm{HCl}$; the deposition of a red precipitate indicated the presence of phlobatannins [4].

\section{Test for coumarins}

In a small test tube, $300 \mathrm{mg}$ of plant extract was covered with filter paper moistened with $1 \mathrm{~N} \mathrm{NaOH}$. The test tube was placed for few minutes in a boiling water bath. After removing the filter paper, it was examined under ultraviolet (UV) light; yellow florescence indicated the presence of coumarins [4].

\section{Test for tannins (ferric chloride reagent test)}

$50 \mathrm{mg}$ of TLM was boiled in $20 \mathrm{ml}$ of distilled water and filtered. A few drops of $0.1 \% \mathrm{FeCl}_{3}$ were added in filtrate and observed for color change; brownish green or a blue-black coloration was taken as evidence for the presence of tannins [5].

\section{Test for flavonoids (ferric chloride test)}

About $0.5 \mathrm{~g}$ of each extract was boiled with $5 \mathrm{ml}$ of distilled water and then filtered. To $2 \mathrm{ml}$ of this filtrate, a few drops of $10 \%$ ferric chloride solution were added. A green-blue or violet colouration indicated the presence of a phenolic hydroxyl group [4].

\section{Test for anthraquinones}

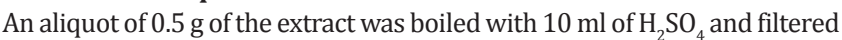
while hot. The filtrate was shaken with $5 \mathrm{ml}$ of chloroform. The chloroform layer was pipetted into another test tube, and $1 \mathrm{ml}$ of dilute ammonia was added. The resulting solution was observed for color changes [5].

\section{Bioassays}

\section{Determination of phenolic content}

Folin-Ciocalteu reagent-based assay was used to determine the total phenol content. To $1 \mathrm{ml}$ extract $(100 \mu \mathrm{g} / \mathrm{ml})$ in methanol, $5 \mathrm{ml}$ of tenfold diluted Folin-Ciocalteu and $4 \mathrm{ml}(75 \mathrm{~g} / \mathrm{ml})$ of $\mathrm{Na}_{2} \mathrm{CO}_{3}$ were added. The mixture was allowed to stand at $20^{\circ} \mathrm{C}$ for 30 minutes and the absorbance was recorded at $756 \mathrm{~nm}$ by UV-spectrophotometer $[6,14]$. $1 \mathrm{ml}$ aliquots of $10,20,40,60,80$, and $100 \mu \mathrm{g} / \mathrm{ml}$ gallic acid solution were used to prepare standard calibration curve. Total phenol value was obtained from the regression equation and expressed as $\mathrm{mg} / \mathrm{g}$ gallic acid equivalent using the formula $\mathrm{C}=\mathrm{cV} / \mathrm{M}$ where $\mathrm{C}=$ Total content of phenolic compounds in mg/g GAE, c=The conc of gallic acid (mg/L) established from the calibration curve, $\mathrm{V}=$ Volume of extract $(0.5 \mathrm{ml})$, and $\mathrm{M}=$ Weight of pure plant extract. The linear regression equation for a straight line is, $\mathrm{Y}=\mathrm{mx}+\mathrm{c}$ where $\mathrm{Y}=\mathrm{Absorb}$ ance of extract, $\mathrm{m}=$ Slope of the calibration curve, $\mathrm{x}=$ Concentration of extract, and $\mathrm{c}=$ Intercept. Using this regression equation, concentrations of extracts were calculated. From the calculated values of concentration of each extract, the total phenolics content was calculated.

\section{Ferric reducing antioxidant power assay (FRAP)}

The reducing antioxidant power of the extracts was determined by the method of Oyaizu $[7,15]$. Various concentrations of extracts $(10-100 \mu \mathrm{g} / \mathrm{ml})$ in $1 \mathrm{ml}$ of distilled water were mixed with phosphate buffer $(3.0 \mathrm{ml}, 0.2 \mathrm{M}, \mathrm{pH} 6.6)$ and potassium ferricyanide [K3Fe(CN)6 $(2.5 \mathrm{ml}, 1 \%)$. The mixture was incubated in an incubator at $50^{\circ} \mathrm{C}$ for 20 minutes. After incubation, $2.5 \mathrm{ml}$ of trichloroacetic acid (10\%) was added to the mixture and centrifuged for 10 minutes at $3000 \mathrm{rpm}$. The upper layer of solution $(2.5 \mathrm{ml})$ was mixed with distilled water $(2.5 \mathrm{ml})$ and $\mathrm{FeCl}_{3}(0.5 \mathrm{ml}, 0.1 \%)$. The samples absorbance was read at $700 \mathrm{~nm}$ against a blank using UV-spectrophotometer. Gallic acid was used as a standard.

Reducing antioxidant power was determined using following formula: $(\mathrm{Ac}-\mathrm{As} / \mathrm{Ac}) \times 100$ where "Ac" is the absorbance of control and "As" is absorbance of sample.

\section{Scavenging activity against DPPH radical}

DPPH radical scavenging activity of crude extracts was measured $[8,9]$. Extract solutions were prepared by dissolving $0.05 \mathrm{~g}$ of dry extract in $50 \mathrm{ml}$ of methanol. An aliquot of $2 \mathrm{ml} 0.004 \%$ DPPH solution in methanol was mixed with $1 \mathrm{ml}$ of plant extracts in methanol at various concentrations $(100-1000 \mathrm{ng} / \mathrm{ml})$ and incubated at $25^{\circ} \mathrm{C}$ for 30 minutes. The absorbance of the text mixture was read at $517 \mathrm{~nm}$ using a spectrophotometer against a DPPH control containing only $1 \mathrm{ml}$ of methanol in place of the extract. All experiments were repeated thrice along with Gallic acid (standard). The percentage inhibition was calculated using the following expression; percentage inhibition $=(\mathrm{A}$ blank-A sample/A blank $\times 100$ where A blank and A sample stand for the absorption of the blank and absorption of the tested extract solution respectively.

\section{Nitric oxide radical scavenging activity}

At physiological $\mathrm{pH}$, nitric oxide generated from aqueous sodium nitroprusside (SNP) solution interacts with oxygen to produce nitrite ions, which may be quantified by the Griess-Ilosvay reaction (Garratt et al., 1964). The reaction mixture contained $10 \mathrm{mM}$ SNP, phosphate- buffered saline (pH-7.4) and various doses (i.e., 10, 20,40,60, 80, and 100) of the test solution in a final volume of $3 \mathrm{ml}$. After incubation for 150 minutes at $25^{\circ} \mathrm{C}, 1 \mathrm{ml}$ sulfanilamide $(0.33 \%$ in $20 \%$ glacial acetic acid $)$ was added to $0.5 \mathrm{ml}$ to the incubated solution and allowed to stand for 5 minutes. Then, $1 \mathrm{ml}$ of naphthyl ethylenediamine dihydrochloride (NED) $(0.1 \% \mathrm{w} / \mathrm{v})$ was added and the mixture was incubated for 30 minutes at $25^{\circ} \mathrm{C}$. The pink chromophore generated during diazotization of nitrite ions with sulfanilamide and subsequent coupling with NED was measured. Nitric oxide radical scavenging activity determined using following formula: 
"Ac" is the absorbance of control and "Ao" is absorbance of sample.

Calculation of inhibition concentration $\left(\mathrm{IC}_{50}\right)$ values for scavenging assays

$\mathrm{IC}_{50}$ value is defined as the amount of antioxidant necessary to decrease the initial concentration of the free radical activity by $50 \%$. IC $\mathrm{I}_{50}$ values were calculated from the graph plotted between percentage scavenging activities against the concentrations of the samples by the formula $\mathrm{Y}=\mathrm{mx}+\mathrm{C}$ where $\mathrm{Y}=$ Percentage Inhibition, $\mathrm{x}=$ Concentration, $\mathrm{C}=$ Constant, $\mathrm{m}=$ Coefficient (http://www.ic50.tk/).

\section{In vitro antimicrobial susceptibility assay}

\section{Microbroth dilution assay}

The antifungal susceptibility of the fungi to various fractions or the purified component was assayed by the microbroth dilution method [10]. Spores of Aspergillus were harvested from 96 hrs cultures and their number adjusted to $1 \times 10^{6}$ per ml. The Sabouraud Dextrose and Potato Dextrose medium were dissolved in glass double distilled water and autoclaved at 10 psi for 15 minutes. A volume of $100 \mu \mathrm{l}$ of medium was added to the wells of cell culture plates. The different concentrations of the extract, fractions, or the purified compound were prepared in duplicate wells, and then the wells were inoculated with 10 $\mu \mathrm{l}$ of spore suspension (prepared in phosphate buffer saline). The plates were incubated at $37^{\circ} \mathrm{C}$ and examined macroscopically after $48-72 \mathrm{hrs}$ for the growth of Aspergillus mycelia. The activity was represented as negative if growth was there and positive if medium appeared clear without any growth of Aspergillus.

\section{Antifungal assay}

About $200 \mathrm{mg}$ dried extracts from different solvents was dissolved in dimethyl sulfoxide and water in 1:1 and subjected to antifungal screening by microbroth dilution assay for fungus Aspergillus niger and Aspergillus fumigatus. The culture media used for antifungal testing were potato dextrose agar and broth for $A$. fumigatus whereas sabouraud dextrose agar and broth for $A$. niger

The fungal stock cultures were maintained on PBS, which were stored at $4^{\circ} \mathrm{C}$. The spores of Aspergillus were harvested from $96 \mathrm{hrs}$ cultures and treated with extracts in a 96 -well culture plate by serial dilution method. The wells of the culture plates were inoculated with 96 total numbers of $1 \times 10^{6}$ conidia in $1.0 \mathrm{ml}$. The plates were incubated at $37^{\circ} \mathrm{C}$ and examined microscopically after $48 \mathrm{hrs}$ for the growth of Aspergillus mycelia. The wells were prepared in triplicate for each concentration. $1 \mathrm{mg} / \mathrm{ml}$ stock solution of Amphotericin B and fluconazol was used in assay as a standard control drug.

\section{Solvent-solvent fractionation}

Solvent-solvent fractionation was used for methanol extract as a preliminary separation to simplify complex extracts with promising activity by fractionating chemical compounds into broad groups based on their solubility. The residue was dissolved in 1:1 mixture of chloroform and water and two phases was separated by separating funnel. Water fraction was mixed with equal volume of n-butanol in a separating funnel to yield water (W) and butanol (BT) fraction. The chloroform fraction was taken to dryness and after complete drying was extracted with equal volume of hexane and $10 \%$ water in methanol. This yielded hexane (HE) fraction and $10 \%$ water/methanol was further diluted to $20 \%$ water/methanol by addition of water. This was mixed with equal volume of carbon tetrachloride in a separating funnel; yielded carbon tetrachloride fraction (CT) and $20 \%$ water/methanol was further diluted to $35 \%$ water/methanol with water by addition of water and was mixed with equal volume of chloroform in separating funnel, yielded chloroform (CH) and 35\% water/methanol fraction(W/M) (Dabur et al., 2009). In all cases, equal volumes of solvents were used and extraction process repeated with a small volume three times. Minimum inhibitory concentration (MIC) was done after dryness and weighing the fraction showing in Table $5 \mathrm{in} \mathrm{mg} / \mathrm{ml}$.

\section{RESULTS}

\section{Phytochemical analysis of plant extracts}

Preliminary phytochemical analysis of leaf extracts (hexane, chloroform, acetone, methanol, and $\mathrm{H}_{2} \mathrm{O}$ ) showed the presence of terpenoids (Table 1). Alkaloids, coumarins, and flavonoids were found in water and methanol. Saponin and anthraquinones were found to be absent in all the tested extracts; phlobatannins was found in non-polar extract. However, antimicrobial activity of extracts may not be easily correlated with specific component but with a mixture of compounds present in these extracts. Results revealed that terpenoids are present in each extract whether it is polar or non-polar. The study revealed that alkaloids and terpenoids are responsible for the antifungal activity in higher plants because the presence of free hydroxyl groups. Consequently, the presence of secondary metabolites or phytochemicals in $P$. dulce validates the antifungal activity in the present study. Nevertheless, it is necessary to identify a significant active compound in pure form that would help further for cure of fungal disease.

\section{Antioxidant activities}

P. dulce leaf extract prepared in different solvents (acetone, methanol, and water) was evaluated for its antioxidant activity by analysis of phenolic content, FRAP, DPPH, and nitric oxide radical scavenging activity assays. All experimental measurements were carried out in triplicate and are expressed as average of three analyses \pm standard deviation; graph was prepared using sigma plot .

\section{Determination of phenolic content}

Results obtained in the present study revealed maximum total phenolic content for methanol extract followed by acetone and water extract as compared to standard (Fig. 1).

\section{FRAP radical scavenging assay}

The reducing power of water is higher as compared to others extract and it is shown in Fig. 2. The result indicates that reducing ability of the

Table 1: Phytochemical screening of $P$. dulce leaves' extracts

\begin{tabular}{|c|c|c|c|c|c|}
\hline P. dulce & Hexane & Chloroform & Acetone & Methanol & Water \\
\hline Alkaloids & - & - & - & ++ & ++ \\
\hline Saponin & - & - & - & - & - \\
\hline Terpenoids & + & ++ & +++ & ++ & ++ \\
\hline Phlobatannins & ++ & ++ & ++ & - & - \\
\hline Coumarins & - & + & ++ & ++ & ++ \\
\hline Tannins & + & + & + & + & + \\
\hline Flavonoids & - & - & ++ & ++ & ++ \\
\hline Anthraquinones & - & - & - & - & - \\
\hline
\end{tabular}

P. dulce: Pithecellobium dulce

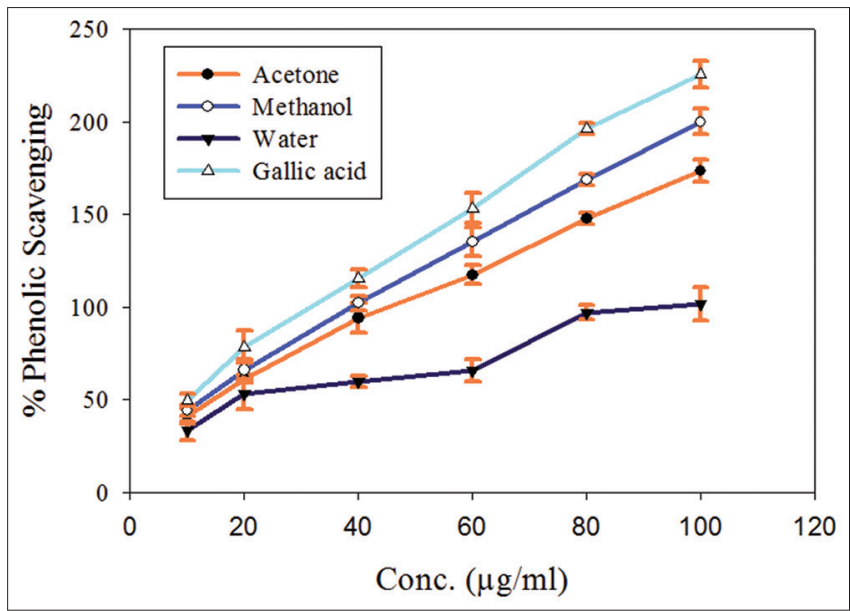

Fig. 1: Total phenolic content of different extracts of Pithecellobium dulce 
extracts increased with the concentration. The water extract showed better reducing power followed by acetone and methanol. $\mathrm{IC}_{50}$ value of methanol and water extract was found to be 13.70 and $50.70 \mu \mathrm{g} / \mathrm{ml}$ (Fig. 2 and Table 2)

\section{DPPH radical scavenging assay}

DPPH radicals are widely used in the model system to investigate the scavenging activity of several natural phytocompounds. The DPPH radical scavenging activity of $P$. dulce leaf extract is shown in Fig. 3 and found maximum in acetone and minimum in water. The $\mathrm{IC}_{50}$ values of scavenging DPPH radicals for water, methanol, and acetone extracts were found to be $49.97,74.89$, and $35.70 \mu \mathrm{g} / \mathrm{ml}$ compared with gallic acid (35.86 $\mu \mathrm{g} / \mathrm{ml})$ which was quite low as compared to all the tested extracts (Table 2 )

\section{Nitric oxide radical scavenging assay}

Nitric oxide scavenging activity was maximum reported in methanol extract and minimum in acetone extract (Fig. 4). The nitric oxide activity $\mathrm{IC}_{50}$ values were found to be higher in acetone $(91.5 \mu \mathrm{g} / \mathrm{ml})$ and water $(81.8 \mu \mathrm{g} / \mathrm{ml})$ than that of gallic acid $(74.7 \mu \mathrm{g} / \mathrm{ml})$ and lower in methanol $(67.41 \mu \mathrm{g} / \mathrm{ml})$ in Table 2 .

\section{Antifungal screening}

Both fungi were screened for MIC against above plant extracts. Stock solution of plant extract was $200 \mathrm{mg} / \mathrm{ml}$. MIC was observed from methanolic extract and was significant and screened furthered after fractionation. The wells containing a concentration of $12.5 \mathrm{mg} / \mathrm{ml}$ extracts of methanol inhibited the visible growth of fungus (Table 3 ). Solvent-solvent fractionation was used for methanolic extract as a preliminary separation to simplify complex extracts with promising activity by fractionating chemical compounds into broad groups based on their solubility shown in Fig. 5 and Table 4.

\section{DISCUSSION}

Plants produce a variety of secondary metabolites such as flavonoids, alkaloids, and coumarins and represent a promising source of antioxidant with antimicrobial agents. Medicines derived from plants have no apparent side effects and are cost effective while modern drugs are associated with kidney and liver dysfunctions. In the present study, the leaf extracts of $P$. dulce exhibited antioxidant and antifungal activity against human pathogenic bacteria.

The use of $P$. dulce in folk medicine suggests that it represents an economic and safe alternative to treat common infectious diseases [2].

Detailed investigations into the active components responsible for the observed antimicrobial activity may open new avenues for drug development and control of antibiotic-resistant pathogenesis. Thus, earlier studies suggest that $P$. dulce possess antioxidant, antibacterial, as well as antifungal activities [12].
Phytochemical screening suggests the presence of biologically important phytoconstituents such as alkaloids, flavonoids, saponins, phlobatannins, and terpenoids. The result of DPPH scavenging activity in this study indicates that the plant was potentially active. The minimum percentage scavenging activity was recorded in the acetone and methanol extract while the minimum percentage scavenging

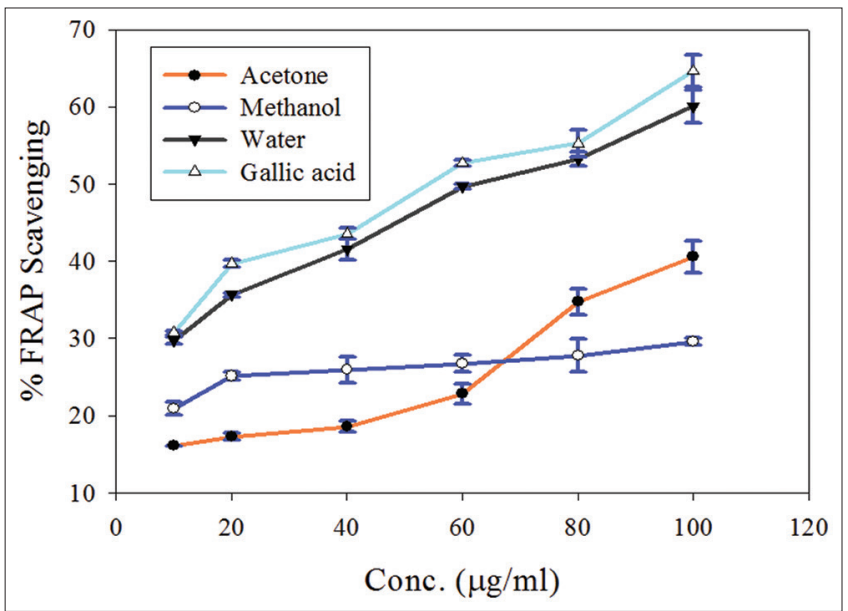

Fig. 2: Ferric reducing antioxidant power assay scavenging activity of different extracts of Pithecellobium dulce

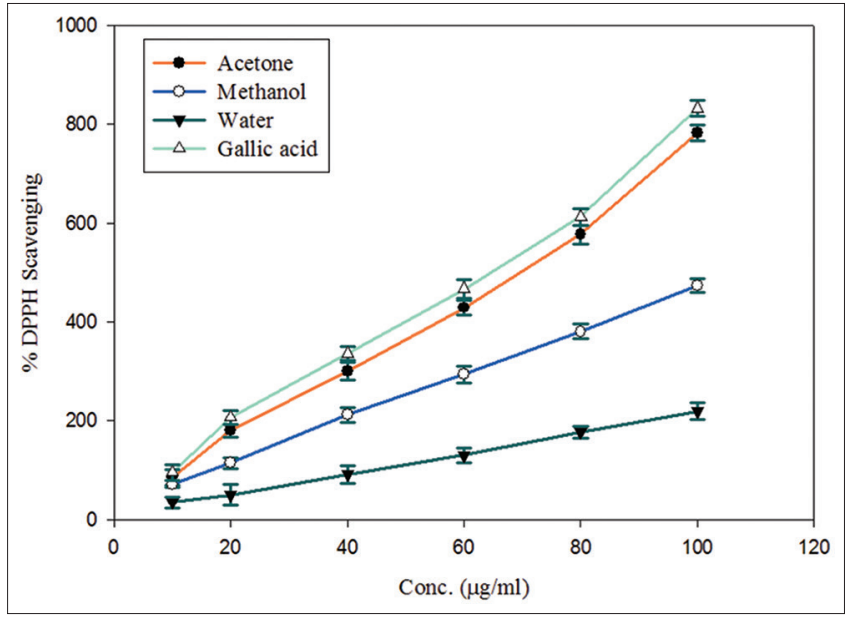

Fig. 3: 1,1-diphenyl-2-picrylhydrazyl Scavenging activity of different extracts of Pithecellobium dulce

Table 2: Scavenging activities of prepared plant extract of $P$. dulce in different solvents

\begin{tabular}{|c|c|c|c|c|}
\hline P. dulce extract & $\begin{array}{l}\text { DPPH radical scavenging } \\
\left(\mathrm{IC}_{50}[\mu \mathrm{g} / \mathrm{ml}]\right)\end{array}$ & $\begin{array}{l}\text { Total phenolic content } \\
\text { (mg GAEs/g dry wt.) }\end{array}$ & $\begin{array}{l}\text { Ferric reduction activity } \\
\text { potential }\left(\mathrm{IC}_{50}[\mu \mathrm{g} / \mathrm{ml}]\right)\end{array}$ & $\begin{array}{l}\text { Nitric oxide radical } \\
\text { scavenging }\left(\mathrm{IC}_{50}[\mu \mathrm{g} / \mathrm{ml}]\right)\end{array}$ \\
\hline Gallic acid & 35.86 & 72.5 & 68.1 & 74.7 \\
\hline Acetone & 49.97 & 52.6 & 72.17 & 91.5 \\
\hline Methanol & 74.89 & 88.2 & 13.70 & 67.41 \\
\hline Water & 35.7 & 20.4 & 50.7 & 81.8 \\
\hline
\end{tabular}

P. dulce: Pithecellobium dulce, DPPH: 1,1-diphenyl-2-picrylhydrazyl, GAEs: Gallic acid equivalents

Table 3: MIC of prepared leaves extract in different solvents against $A$. fumigates and $A$. niger in $\mathrm{mg} / \mathrm{ml}$

\begin{tabular}{llllll}
\hline Fungus & Hexane $(\mathbf{m g} / \mathbf{m l})$ & Chloroform $(\mathbf{m g} / \mathbf{m l})$ & Acetone $(\mathbf{m g} / \mathbf{m l})$ & Methanol $(\mathbf{m g} / \mathbf{m l})$ & Water $(\mathbf{m g} / \mathbf{m l})$ \\
\hline A. niger & 12.5 & 50 & 12.5 & 6.25 & 12.5 \\
A. fumigatus & 12.5 & 50 & 12.5 & 12.5 & 12.5 \\
\hline
\end{tabular}

MIC: Minimum inhibitory concentration, A. niger: Aspergillus niger, A. fumigatus: Aspergillus fumigatus 
Table 4: Solvent-solvent fractionation showing MIC against $A$. fumigates and $A$. niger in $\mathrm{mg} / \mathrm{ml}$. $\mathrm{CCl}_{4}$ - carbon tetrachloride

\begin{tabular}{lllllll}
\hline P. dulce fraction & Water & Butanol & Hexane & CCl $_{\mathbf{4}}$ & Chloroform & 35\% water/methanol \\
\hline A. niger & 1.8 & 1.25 & 25 & 19.37 & 3.7 & 45 \\
A. fumigatus & 1.8 & 0.62 & 12.5 & 19.37 & 3.7 & 11.5 \\
\hline
\end{tabular}

MIC: Minimum inhibitory concentration, A. niger: Aspergillus niger, A. fumigatus: Aspergillus fumigatus, P. dulce: Pithecellobium dulce

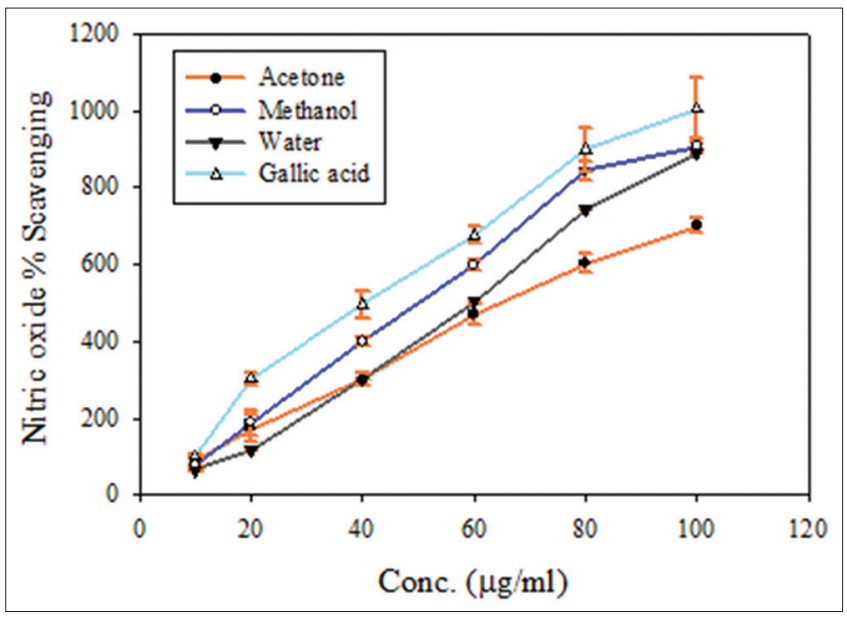

Fig. 4: Nitric oxide scavenging activity of different extracts of Pithecellobium dulce

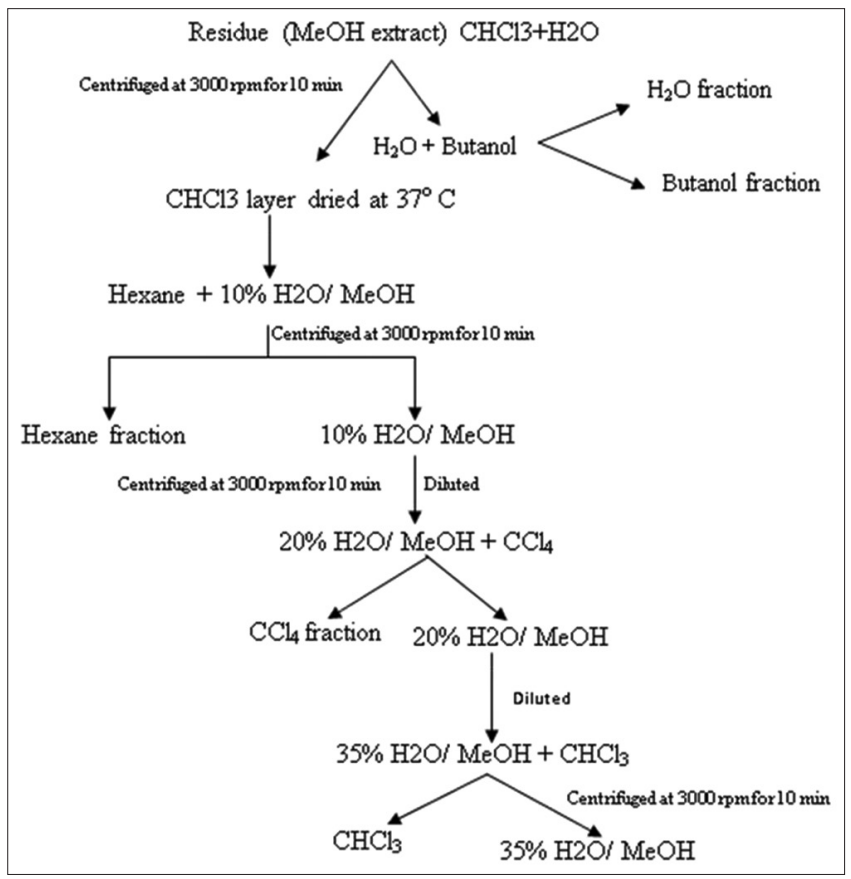

Fig. 5: Systematic flow chart of fractionation of Pithecellobium dulce methanolic extract

activity was found in water extract as compared with gallic acid. Fig. 6 summarizes the comparative antioxidant activities of $P$. dulce extract in different solvents

In humans, fungal infections range from superficial to deeply invasive or disseminated and have increased dramatically in recent years. The results of the study indicated that $P$. dulce methanolic extract showed effective inhibitory activity against both pathogenic fungi. The fungal strains used in the present study were selected on the basis of their clinical importance. $P$. dulce methanolic extract after fractionation is promising to have antifungal activity of butanol extract as shown in Table 4

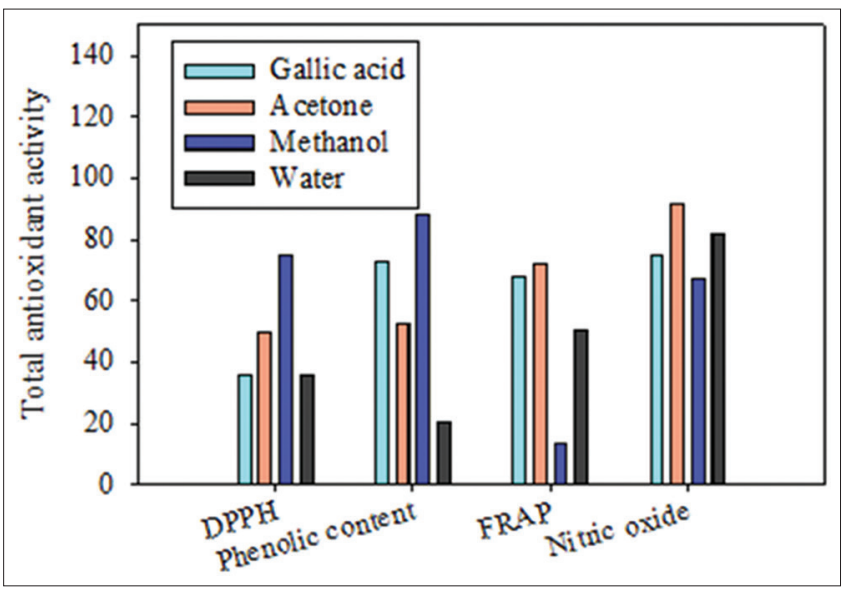

Fig. 6: Total antioxidant activities of different extracts of Pithecellobium dulce

Although screening of Indian medicinal plants has revealed varying degrees of antimicrobial activity against pathogenic and opportunistic microorganisms, there is still a lack of experimental scientific studies confirming the possible antimicrobial properties of a great number of these remedies. Hence, the present analysis clearly indicated the antioxidant and antifungal effect of $P$. dulce, thereby enhancing the possibility of finding and exploring potent bioactive molecule possessing antifungal property.

\section{CONCLUSION}

The present study systematically authenticates the presence of secondary metabolites, antioxidant activities, and antifungal activity of the traditionally important plant, $P$. dulce. The results provide an important basis for the use of polar solvent, i.e., methanol and water extracts of the tested plant species for the antioxidant activity and antifungal compounds which could be useful for the development of new antimicrobial drugs. However, further studies associated with isolation and detection of the particular compounds responsible for the antimicrobial activity are underway by fractionation scheme. The study recommended that $P$. dulce showed signs of significant antifungal activity and properties that support conventionally use of this plant. Further research focuses on elucidating purified active compound from plant which could be a useful source for the development of novel antifungal agent because that folk medicine, cost effective, can be as effective as modern allopathic medicine to treat pathogenic microorganism.

\section{ACKNOWLEDGMENTS}

This project was supported by the Biochemistry Department, M.D.U. Rohtak and I am grateful to Prof. Rajesh Dabur (Biochemistry Department) for providing instrument, solvents, and chemicals.

\section{REFERENCES}

1. Amghalia E, Nagi AA, Shamsudin MN, Radu S, Rosli R, Neela V, et al. Multiplex PCR assays for the detection of clinically relevant antibiotic resistance genes in Staphylococcus aureus isolated from Malaysian hospitals. Res J Bio Scie 2009;4(4):444-8.

2. Pillai SS. Evaluation of antimicrobial activity of Pithecellobium dulce pod pulp extract. Asian J Pharm Clin Res 2014;7(1):32-7. 
3. Harborne JB. Phytochemical Methods. $3^{\text {rd }}$ ed. New York: Chapman and Hall Int; 1998.

4. Trease GE, Evans WC. Pharmacognosy. $13^{\text {th }}$ ed. London: ELBS/ Bailliere Tindall; 1989. p. 345-6.

5. Sofowora A. Recent trends in research into African medicinal plants. J Ethnopharmaco 1993;38:197-208.

6. McDonald S, Prenzler PD, Autolovich M, Robards K. Phenolic content and antioxidant activity of olive extracts. Food Chem 2001;73:73-84.

7. Oyaizz M. Studies on products of browning reactions. Antioxidant activities of products of browning reaction prepared from glucosamine. Jap J Nutr 1996;44:307-15.

8. Braca A, Tommasi ND, Bari LD, Pizza C, Politi M, Morelli I. Antioxidant principles from Bauhinia terapotensis. J Na Prod 2001;6:892-5.

9. Rajeswara RP, Sambasiva RE, Yasodhara B, Dasari VS, Mallikarjuna RT. In-vitro antioxidant and antibacterial activities of different fractions of
Heliotropium indicum L. J Pharm Res 2001;5:1051-3.

10. Barchiesi F, Colombo AL, McGough DA, Fothergill AW, Rinaldi MG. In vitro activity of itraconazole against fluconazole-susceptible and -resistant Candida albicans isolates from oral cavities of patients infected with human immunodeficiency virus. Antimicrob Agents Chemother 1994;38(7):1530-3.

11. Arif T, Bhosale JD, Kumar N, Mandal TK, Bendre RS, Lavekar GS, et al. Natural products - antifungal agents derived from plants. J Asian Nat Prod Res 2009;11(7):621-38

12. Sukantha TA, Sripathi KS, Ravindran NT, Balashanmugam P. Evaluation of in vitro antioxidant and antibacterial activity of Pithecellobium dulce Benth fruit peel. Int J Curr Res 2011;3(1):378-82.

13. Katekhaye SD, Kale MS. Antioxidant and free radical scavenging activity of Pithecellobium dulce (Roxb.) Benth wood bark and leaves. Free Radic Antioxid 2012;2(3):47-57. 